\title{
Linking plate tectonic settings and microbial functions on a global scale
}

\author{
DEBORAH BASTONI ${ }^{1}$, JOY BUONGIORNO ${ }^{2}$, SHAUNNA \\ MORRISON $^{3}$, ROBERT HAZEN ${ }^{3}$, ANIRUDH PRABHU ${ }^{4}$, \\ AHMED ELEISH ${ }^{4}$, PETER BARRY ${ }^{5}$, DAVID BEKAERT ${ }^{5}$, \\ SABIN ZAHIROVIC ${ }^{6}$, ANGELINA CORDONE ${ }^{1}$ AND \\ DONATO GIOVANNELLI ${ }^{7}$ \\ ${ }^{1}$ University of Naples Federico II \\ ${ }^{2}$ Maryville College \\ ${ }^{3}$ Geophysical Laboratory, Carnegie Institution for Science \\ ${ }^{4}$ Rensselaer Polytechnic Institute \\ ${ }^{5} \mathrm{MC} \& \mathrm{G}$, Woods Hole Oceanographic Institution \\ ${ }^{6}$ University of Sydney \\ ${ }^{7}$ Monte Sant'Angelo \\ Presenting Author: deborah.bastoni@gmail.com
}

Microbial communities carry out the core redox reactions that control biogeochemical cycles of elements and nutrients mainly thanks to enzymes that use transition metals as catalytic cofactors, suggesting a direct link with the environmental availability of those metals. As Earth's Biosphere and Geosphere have coevolved over time, metal concentrations have changed, influencing surface redox conditions as well as cycling of elements and volatiles, leading to new and more abundant reductant-oxidant pairs, probably influencing the evolution and distribution of metabolic processes. The delivery of life's relevant transition metals is controlled to a first order by tectonic processes. We present here geochemical and microbiological coupled analysis of data from over 250 geothermal locations globally. Our work aims to look for links between the delivery of transition metals to the surface through plate tectonics and microbial functional diversity. Our dataset reveals direct correlations between key microbial functions and differences in the delivery of the key metal cofactors to the surface of our planet. Understanding which processes makes key elements available for life, and how these affect the distribution of microbial enzymes critical for biogeochemistry, will allow to shed light on the interaction between Earth's Geosphere and Biosphere, opening new doors not only on better understanding our planet, but also on what are the characteristics to look for in a planet potentially suitable for life. 